\title{
Reply to the Letter to the Editor of V. Kumar et al. concerning "Primary cervical decompression surgery may improve lumbar symptoms in patients with tandem spinal stenosis" by Inoue T, et al. (Eur Spine J; 2021 Jan 6. doi: 10.1007/s00586-020-06693-0)
}

\author{
Taro Inoue ${ }^{1} \cdot$ Shiro Imagama ${ }^{1}$
}

Received: 23 March 2021 / Accepted: 26 March 2021 / Published online: 8 April 2021

(c) The Author(s), under exclusive licence to Springer-Verlag GmbH Germany, part of Springer Nature 2021

We thank the authors for their interest in our study and sincerely appreciate your comments. We preoperatively conducted myelography and computed tomography (CT) for all patients with lumbar spinal stenosis (LSS) to accurately assess for lumbar compression lesions. In addition, we have long been aware of the complications of cervical SS (CSS) in patients with LSS. Thus, we performed myelography and $\mathrm{CT}$ of both the cervical and lumbar spine. However, as you pointed out, the effect of radiation exposure should not be ignored. We will consider limiting the indications for myelography in the future. Thank you for your valuable feedback.

Your question regarding the sex difference in the three groups is valid but very difficult to answer. In our study, no significant difference in sex was found between the relapsed and maintained-improvement groups. Furthermore, no significant differences were detected between the non-improved and temporary or maintained-improvement group (relapsed group + maintained-improvement group). Based on these findings, the difference between the non-improvement and relapsed groups may not be clinically relevant.

As you pointed out, this study was a retrospective study with a small sample size. Therefore, we obtained only insufficient evidence on the preferential cervical decompression in patients with tandem SS (TSS). However, improvements in lumbar symptoms after cervical cord decompression were first reported by Epstein et al. [1] in 1984. Since then, some studies have suggested that prioritized cervical surgery has a lower

Shiro Imagama

imagama@med.nagoya-u.ac.jp

Taro Inoue

bluesdrivemonster@hotmail.com

1 Department of Orthopaedic Surgery, Nagoya University Graduate School of Medicine, 65, Tsurumai, Showa-ku, Nagoya, Aichi 466-8550, Japan lumbar reoperation rate than prioritized lumbar surgery in patients with TSS [2, 3]. In addition, improvement in nonspecific low back pain following cervical decompression surgery for patients with CSS has been reported [4]. Moreover, Kim et al. [4] found reduced central sensitization and exaggeration of the pain response in the lumbar area and/or improvement in global spine alignment after cervical decompression surgery. Although our study has insufficient evidence, we anticipate that our report nevertheless contributes useful data on prioritized cervical decompression surgery in patients with TSS.

\section{Compliance with ethical standards}

Conflict of interest None of the authos has anu potential conflict of interest.

\section{References}

1. Epstein NE, Epstein JA, Carras R, Murthy VS, Hyman RA (1984) Coexisting cervical and lumbar spinal stenosis: diagnosis and management. Neurosurgery 15:489-496. https://doi.org/10.1227/ 00006123-198410000-00003

2. Li H, Chen Z, Li X, Liu T, Shen B, Huang Y, Wu D (2017) Prioritized cervical or lumbar surgery for coexisting cervical and lumbar stenosis: Prognostic analysis of 222 case. Int J Surg 44:344-349. https://doi.org/10.1016/j.ijsu.2017.07.027

3. Luo CA, Kaliya-Perumal AK, Lu ML, Chen LH, Chen WJ, Niu CC (2019) Staged surgery for tandem cervical and lumbar spinal stenosis: Which should be treated first? Eur Spine J 28:61-68. https://doi.org/10.1007/s00586-018-5795-6

4. Kim CH, Chung CK, Lee U, Choi Y, Park SB, Jung JM, Hwang SH, Yang SH (2018) Postoperative Changes in Moderate to Severe Nonspecific Low Back Pain After Cervical Myelopathy Surgery. World Neurosurg 116:e429-e435. https://doi.org/10.1016/j.wneu.2018.04.224

Publisher's Note Springer Nature remains neutral with regard to jurisdictional claims in published maps and institutional affiliations. 